\title{
CRITICAL INFRASTRUCTURE RISK IN NHS ENGLAND: PREDICTING THE IMPACT OF BUILDING PORTFOLIO AGE
}

\author{
Grant R. W. MILLS ${ }^{\text {a,* }}$, Lipika DEKA ${ }^{\text {b }}$, Andrew D. F. PRICE ${ }^{\text {b }}$, \\ Sameedha RICH-MAHADKAR b,c, Efthimia PANTZARTZIS ${ }^{b}$, Peter SELLARS d \\ ${ }^{a}$ The Bartlett School of Construction and Project Management, University College London, 1-19 \\ Torrington Place, London WC1E 7HB, United Kingdom \\ ${ }^{b}$ School of Civil and Building Engineering, Loughborough University, Epinal Way, Leicestershire \\ LE11 3TU, United Kingdom \\ ${ }^{c}$ Nottingham University Hospitals NHS Trust, Strategy Corporate Team, City Hospital campus, \\ Hucknall Road, Nottingham, NG5 1PB \\ ${ }^{d}$ NHS Estates \& Facilities Policy Division Group Operations and Assurance Directorate, 1 N12 Quarry \\ House, Leeds LS2 7UE, United Kingdom
}

Received 2 August 2013; accepted 21 March 2014

\begin{abstract}
NHS Trusts in England must adopt appropriate levels of continued investment in routine and backlog maintenance if they are to ensure critical backlog does not accumulate. This paper presents the current state of critical backlog maintenance within the National Health Service (NHS) in England through the statistical analyses of 115 Acute NHS Trusts. It aims to find empirical support for a causal relationship between building portfolio age and year-on-year increases in critical backlog. It makes recommendations for the use of building portfolio age in strategic asset management. The current trend across this sample of NHS Trusts may be typical of the whole NHS built asset portfolio and suggests that most Trusts need to invest between 0.5 and 1.5 per cent of income (depending upon current critical backlog levels and Trust age profile) to simply maintain critical backlog levels. More robust analytics for building age, condition and risk-adjusted backlog maintenance are required.
\end{abstract}

KEYWORDS: Asset management; Backlog; Healthcare; Performance; Service life planning; Value

\section{INTRODUCTION}

\section{Asset management in NHS English}

In 2010/11, the English government spent circa $£ 121$ bn on healthcare, which was delivered from a national building portfolio valued at $£ 83 \mathrm{bn}$ and cost £7.2bn in maintenance (Harker 2012; Appleby et al. 2009). After a period of continuous growth in funding, the future NHS funding scenario is not very promising (Appleby et al. 2009), although built assets must remain safe and fit for purpose. The Care Quality Commission (2010) stated that healthcare providers must "take account of any relevant design, technical and operational standards and manage all risks in relation to the premises". In addition, inspectors measure the compliance of assets to ensure "safety and suitability of premises", by means of "suitable design and layout", "security measures", "adequate maintenance" and "proper operations [of]... premises... and grounds".

\footnotetext{
* Corresponding author. E-mail: g.mills@ucl.ac.uk
}

The Department of Health (2008) states that premises must: be "safe", "clean and appropriate"; "prevent and control infection"; be "accessible" and "promote... wellbeing" and that the "closure of rooms, wards, departments and premises" must be well managed.

Many Trusts are reviewing the value of their assets, looking for ways to deal with financial challenges and to cope with rising demand. The costs and risks associated with asset condition require further investigation, as do: life-cycle scenario planning (Bjorberg, Verweij 2009); the application of robust predictive analytics (Lavy, Shohet 2007); and the realisation of best portfolio and service whole life value (through acquisition, maintenance, adaptation and disposal strategies) (BSI 2000; BSI 2001; BSI 2002; BSI 2004a,b). Facilities management organisations have embraced new total asset management approaches such as agile, lean and enterprise (Price 2007; Price, May 2008) 
to forecast and cope with unpredictable change and are applying new computer-aided design and maintenance management systems, although some patients faced with dilapidated facilities may ask if enough is being spent.

Greater recognition must be given to measuring whole-life building portfolio value and risk to leverage timely and appropriate capital investment.

The challenge for all NHS organisations, especially those moving towards Foundation Trust status, is to reduce critical backlog maintenance, eradicating high and significant risk, in ways that are aligned with their unique financial, operational and clinical strategies. Many will most likely have to adapt to new public-private partnership models as after 2015 , there will be relatively little central public capital and NHS Foundation Trusts will operate independently from state control (Department of Health 2012a). The NHS currently spends about $£ 450$ million annually on backlog maintenance. Although little is known about its impact on the rate of depreciation of assets; or the impact of counter measures, such as the use of operating revenue to fund regular predictive, preventative and corrective maintenance, capital investment or quick dis-investment and sale. The question is how much money should be spent on preventative and corrective maintenance and how should critical backlog be eradicated and prevented from re-escalating?

\section{Investment in a sustainable future}

Escalating demand for healthcare systems, and the depreciation and obsolescence of existing built healthcare assets are creating an emerging capacity gap the world over. In addition, the need to reduce greenhouse gas emissions, save energy, generate new renewable sources, look to more renewable raw materials and reduce waste are some of the challenges that the NHS must address if it is to cope with legislative and commercial pressures. The 2012 Kyoto commitment and the EU energy performance of buildings directive are driving minimum energy performance levels and systems of certification. These new measures will almost certainly impact on existing and new NHS capital and revenue spending on buildings.

\section{Key terminology}

This paper aims to analyse empirical data to explore the relationship between NHS Trust building portfolio age and critical backlog and furthermore makes recommendations for more advanced and predictive approached that use age as a proxy for asset condition. As such, it draws on the field of asset management (Sharp et al. 1999; Yusuf et al. 1999) and enterprise asset management systems (Campbell et al. 2011). In addition, within a regulators systems domain (Baldwin et al. 2012) it addresses how providers, commissioners and policy makers could benchmark the impact of age on asset maintenance programmes, to monitor risk-adjusted backlog, potential failure and depreciation.

The central concepts applied within this paper are defined below.

National Health Service Trust (NHS Trust) - a healthcare provider directed by an executive and non-executive board on behalf of a regional patient population. They include both publicly owned (NHS Trusts) and independent (NHS Foundation Trusts).

Department of Health (DH) - a ministerial department, supported by 25 agencies and public bodies. They lead, shape and fund health and care in England through the creation of national policies and legislation. They are responsible and accountable for the integrity of the health system, service and asset improvement.

Maintenance - the regular work done to keep a building in good or minimum condition by fixing the unscheduled breakdown of mechanical, plumbing or electrical devices and routine scheduled, preventative and predictive operations that mitigate against the risk of breakdown and which assures service performance.

Backlog - accumulated maintenance or the proportion of an asset (elements and sub-elements) that falls below an acceptable minimum performance condition standard (condition B which is defined as sound, operationally safe and exhibits only minor deterioration) and compliant with mandatory fire safety requirements and statutory safety legislation.

Critical backlog - a risk-adjusted maintenance cost apportioned to an asset portfolio, building, block, element or sub-element that is classed as having a backlog score that presents a high and significant backlog risk. It is calculated using a $5 \times 5$ matrix of probability (or likelihood) and consequence (impact) that is assessed using a standard risk-based methodology (NHS Estates 2004). Investment is then often targeted to reduce critical backlog.

Service-life - a period of time from installation to disposal during which a built infrastructure asset (or its parts) are used and continue to meet or exceed minimum performance requirements. Estimating service-life is often a negotiation between diverse stakeholder views. 
Strategic asset management - a systematic planning, design, construction and operation process which seeks to ensure that the service-life of all built infrastructure assets (and its parts) will equal or exceed its design life, while taking into account (and preferably optimising) the life cycle costs and performance of the building in meeting the business objectives. It aims to reduce the overall cost of high investment assets and to reduce premature obsolescence.

\section{BACKLOG MAINTENANCE IN NHS HEALTHCARE INFRASTRUCTURE ASSETS}

\section{NHS England's building portfolio}

More than a fifth of the NHS building portfolio was built prior to the birth of NHS in 1948 and a few buildings date back to 1700 . The condition of the NHS building portfolio varies and the situation is considered by some to be getting worse as backlog accumulates. At present, $17 \%$ of buildings are considered to be "functionally unsuitable" (Department of Health 2010), although this is notoriously difficult to assess.

Age is an important factor contributing to the ever-increasing backlog (critical and otherwise). It has been recognised as a significant factor in the maintenance of all types of infrastructure assets, for example roads and highways (National Surface Transportation Policy and Revenue Study Commission 2007).

Building condition deteriorates over years because of continuous wear and tear as a result of continued use over time as well as due to environmental and climatic effects. Furthermore, old buildings require additional investment to meet new building regulations, design standards, and to accommodate up-to-date technical and IT infrastructure. In the present climate there may be a propensity to focus on static short-term demands, rather than more dynamic long-term organisational value. This tendency is driven by uncertainty and is exacerbated in an industry such as healthcare, which is characterised by complex building types, multiple interconnected services, many spatial configurations and continuous innovation. One consequence is that the effective life span of healthcare buildings is shortening and contributing to technical, social or economic obsolescence. Asset value is likely to diminish and depreciate over time as expectations rise, technology changes, maintenance costs increase, intolerance of disruption and elemental components become obsolete.
Trusts are responsible for their own liabilities and the costs of failure (NHS Estates 1997). In cases of non-compliance with statutory requirements, Chief Executives and managers can be criminally prosecuted. The 12-month inquiry by Sir Robert Francis QC, which cost $£ 13 \mathrm{~m}$ and was the fifth of its kind, highlighted the consequences (Francis 2013). Specifically, non-compliance with environment and equipment standards, the safety risks presented by refurbishment, service failings attributed to activity volume and infrastructure capacity, lack of recognition and direct measures of environmental issues (and their impact on outcomes), problems in commissioning, unsafe staffing ratios, complicated and duplicated assessment regimes, and limited resources to complete physical inspection by qualified assessors (Francis 2013).

In order to ensure that the physical condition of the NHS building portfolio is accurately assessed and reported to policy makers, the $\mathrm{DH}$ has in place a risk-based methodology (NHS Estates 2004) that is used by most NHS Trusts in England. This prescribes a detailed survey of physical condition and associated risk, compliance with mandatory fire safety requirements and statutory safety legislation, and allocates a condition ranking at the level of the sub elements.

\section{State-of-the-art review}

The central tenet of this paper is that building portfolio age has a significant impact on critical backlog. Previous studies have inferred that, the older the facility, the higher the maintenance cost and cumulative backlog, although few authors have explicitly stated it. Advances in the development of analytical software and their competent application to real life problems are seemingly progressing faster than the academic literature on the subject. Grey literature (Bourke et al. 2005) and off-the-shelf knowledge management software allow systematic approaches to condition, maintenance and renovation assessment and cost (CalCon 2014), while bespoke commercial service offerings, privatepublic partnerships (Interserve 2014; Circle 2014) and coordinated assessment mechanisms (BSI and BCIS 2008) may be achieving strategic and operational success. According to Bahr et al. (2008) and Lennerts (2010) issues remain in setting predictive asset maintenance budgets. More recently, Bossmann and Lennerts (2013) expressed the challenge in managing data and the complexity of optimising investment in healthcare infrastructure (Diez, Lennerts 2009a, 2009b; Lennerts et al. 2005). 
Age can be considered as a proxy measure when data on condition is missing (National Surface Transportation Policy and Revenue Study Commission 2007). As part of the BEWIS project (Optimised upkeep strategies to maintain value of buildings), Pfründer et al. (2007) and Bahr and Lennerts (2008b) empirically established that the maintenance costs of 20 buildings over their complete life cycle peaked at 30 years and showed that existing calculation methods deliver very inaccurate results for maintenance budgets (Bahr, Lennerts 2008a). Bahr and Lennerts (2008a) were perhaps first to investigate the relationship between building age and maintenance expenditure in addition to the effect of technical equipment or the buildings geometry.

Others such as Lavy and Shohet (2007) have identified major parameters in developing an integrated facilities management model. These include actual age of a building and its level of occupancy, on the performance of facilities and their systems. It points towards a multi-parameter and predictive analytical model that deals with significant complexity. The Indian Health Service (1997) allocate maintenance funding using the modified University of Oklahoma Formula, which takes into account: total space of owned or leased buildings; type of building construction; intensity of use and occupancy of the building; current location of the building; and replacement cost per square meter of the facility. Although age has been stated as a parameter, its importance needs further clarification.

\section{Reconciling value-related perspectives through strategic asset management}

Figure 1 provides an indicative example of three value perspectives over time for a single NHS building asset. Figure 1(i) illustrates two views of built asset condition. The first is of low or medium risk, which may fall below a minimum condition, but remains compliant with mandatory fire safety requirements and statutory safety legislation. The other is of a more catastrophic and serious nature, where there is critical infrastructure risk. In England, DH risk-adjusted backlog methodology (NHS Estates 2004) provides guidance to determine critical backlog (high and significant) through the combination of backlog measures at the scale of a Trust portfolio, building, block, element and sub-element levels (where the former is the aggregate of the later). Figure 1(i) also shows the minimum condition which is grade " $\mathrm{B}$ " " $\mathrm{B}(\mathrm{C})$ " when calculating risk-adjusted backlog and also set by a Premises Assurance Model (PAM) (De- partment of Health 2012b). This details the relevant $\mathrm{DH}$ standards, mandatory fire safety requirements, and statutory safety legislation. Figure 1(ii) shows the cost and financial valuation of the asset. The NHS uses straight line depreciation methods. They apply market value (MV), existing use value (EUV) and depreciated replacement cost (DRC) two of which are depicted. There are a number of different methods of built asset depreciation that take account of the decline in value due to ageing, wear and tear in use, and functional obsolescence. Although, elements and technical systems are valued and depreciate at different rates; for example, a considerable portion of a building's value will relate to engineering services, such as lifts and power installations. These will often have much shorter lives than the fabric of the building. The straight line method of depreciation charges an equal amount of depreciation in each year of an asset's life, by writing off a constant percentage of the asset's original cost. Accelerated and detailed elemental-based approaches may better offset the increasing maintenance cost and essentially equalise the combined charges of both maintenance and depreciation and may be more suitable where assets are highly complex such as in healthcare.

Finally, Figure 1(iii) is the performance output and outcome in terms of both building and clinical services operational terms. In addition there are subjective valuations made by all stakeholders on their satisfaction or dissatisfaction with built assets.

A judgement is often made across these perspectives (i, ii and iii) in strategic asset decision making. For example, taking a reference point in time (as in the line drawn at 9 years on Figure 1) building, investment and clinical decision makers will judge differently value, depreciation and end of service-life for an asset in terms of its condition, importance in accounting terms and outcome performance. So, there is a need to develop better shared analytics that allow future prediction and integrated multi-stakeholder decision making, as opposed to silo benchmarking and responsive practice. As an example, within the existing NHS system in England, the remaining life of the building is determined by an annual independent Government District Valuer (DV), with significant knock on effects. In practice, the remaining service life may not be predicted to optimise condition, cost and performance outcome determinants. Rather, valuation is based on a limited number of factors (often without a full understanding of their interdependency). This study determines the importance 


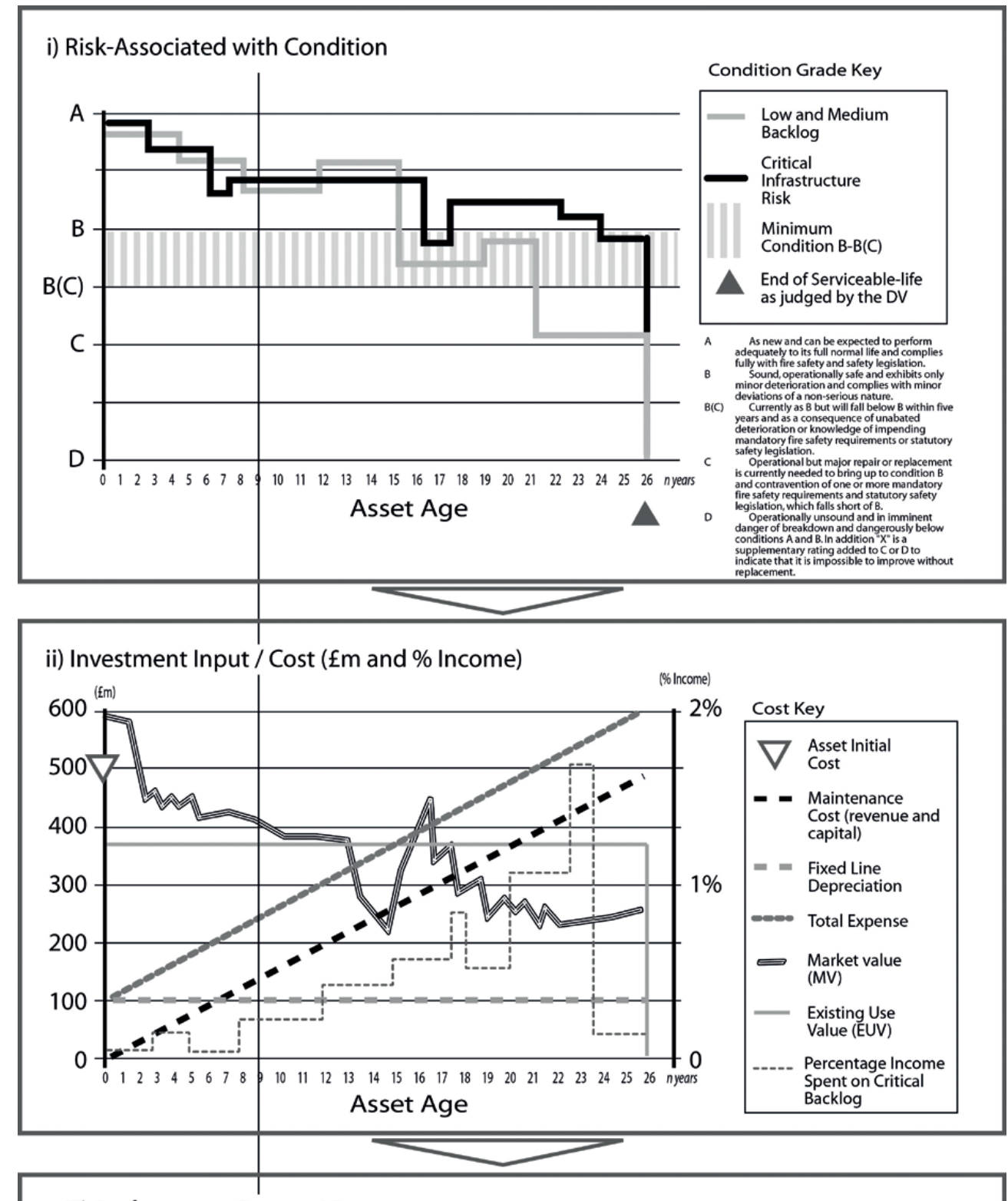

iii) Performance Output / Outcome

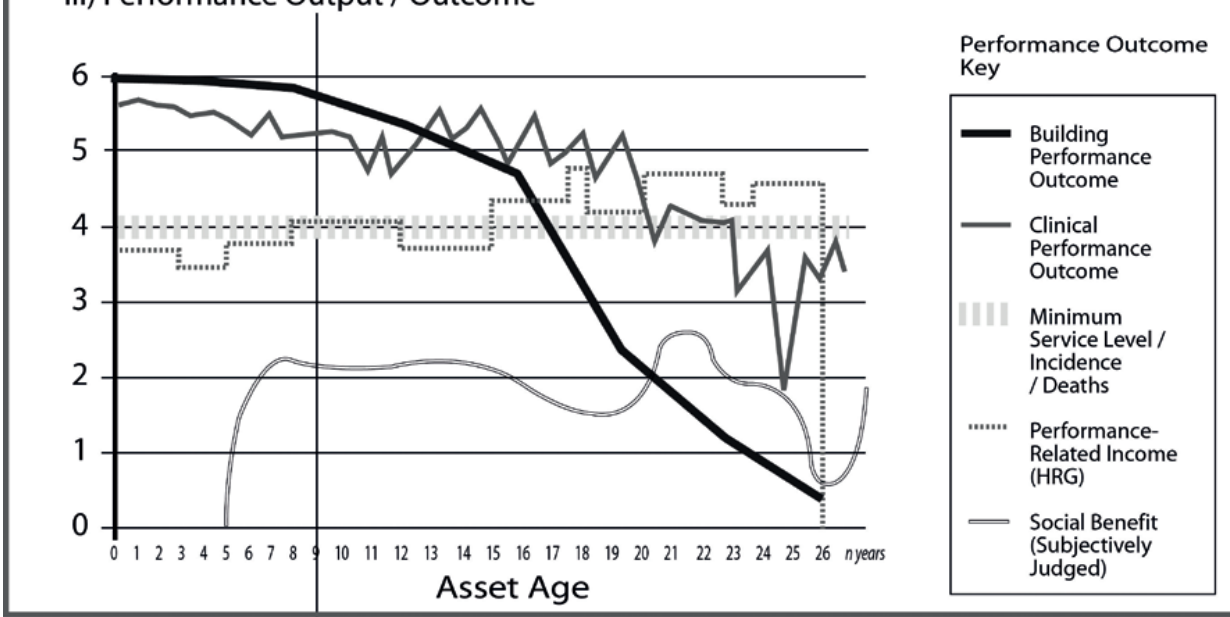

$\sum_{\substack{\text { Reference } \\ \text { Point }}}^{\text {Benchmark }}$

Fig. 1. Three perspectives on the valuation procedure of assets by age 
of investigating how actual age can predict condition, cost and outcome performance and is a highly valuable contribution in determining the remaining serviceable life, if only a rule of thumb.

Research on the impact of built assets on healthcare performance outputs and outcomes is perhaps strongest in the field of evidence based design, with 15 notable major systematic reviews and over 1000 pieces of independent, robust and scientific derived knowledge of this relationship (Ulrich et al. 2004, 2008; Phiri 2006). According to the literature, hospital facility design can positively affect health: design attributes such as the ambient environment (e.g. sound, light and art) and features (e.g. windows, spatial layout, interior corridors and circulation) can have beneficial impacts on behaviour, performance and wellbeing. In additions, negative or harmful impacts on health due to poor hospital facility design quality, inadequate maintenance and failure are clearly evident in the literature (e.g. inadequate lighting and ventilation, poor temperature control and acoustics, and building features which allow or encourage hospital acquired infection).

There are various methods and indices for valuation of the risk-associated with: (i) condition (e.g. mortality, stress and pain, accidents, medical errors); (ii) cost (e.g. length of stay, quality adjusted life years (QALYS) and satisfaction); and (iii) performance (workforce skills, energy consumption, use of drugs and capital cost), although it is at their intersection that little evidence exists to assess return on investment and whole-life value.

Few methods link performance, cost and the risk-associated with asset condition (otherwise known as failure costs, cost of quality or quality cost). Performance and investment are linked by Harvard academics to quantify the costs associated with better built assets. This work has demonstrated a clear impact on the business case for higher capital spending, but not necessarily the case for a higher investment in maintenance or the qualitycost consequence of poor building condition (Berry et al. 2004; Sadler et al. 2011). Only when this evidence gap is addressed will long-term optimum investment decisions across a whole portfolio of assets (that have different age, condition and maintenance requirements) be possible.

\section{PREDICTING BUILDING PORTFOLIO AGE}

The ability to benchmark and predict when age is likely to have a negative impact on value in terms of maintenance/backlog, cost and performance outcomes is highly advantageous.

Investing to minimise, and wherever possible eradicate, critical risk and to deliver optimum value depending on building age must be key if the NHS is to deliver its goal. This will require maintaining or bringing all infrastructure assets up to a suitable minimum condition, and disposing of those that no longer have a serviceable life. This ensures that high and significant risk items do not place patients, staff and visitors at undue risk.

Robust national predictive analytic techniques for building maintenance are needed to better manage current and future situations (Lavy, Shohet 2007). The ambition is to apply advance statistics, modelling, machine learning, and data mining techniques in the analysis of current and historical facilities management data to make predictions about future, or otherwise unknown, events and scenarios (Nyce 2007) to minimise risk and maximise value. This study begins to address this issue by demonstrating the impact of asset age on critical backlog maintenance costs at a NHS building portfolio level.

\section{DATA ANALYSIS}

\section{Method}

To demonstrate the relationship between NHS Trust building portfolio age and critical backlog maintenance cost, publicly available data called the NHS Hospital Estates and Facilities Statistics (2008-2011) and data provided by the DH were utilised. All cost figures for NHS Trust income and Trust building portfolio backlog were adjusted for regional variations and inflation in order to standardise the subsequent analysis. From the initially identified 160 Acute NHS Trusts, those with missing data (including some that no longer exist) and other data anomalies were excluded, resulting in a final sample of 115 Acute Trusts (which included both Foundation and Non-Foundation Trusts). All 115 Trusts were analysed to determine average change in critical backlog, estimated cost and actual spent on critical backlog maintenance.

Of these 115 Trusts, 15 Trusts were identified as outliers. Outliers were Trusts that had a significant change (increase as well as decrease) in their critical backlog during the period and had spent (as a percentage of their income) significantly more than the average; these were called significant change trusts. 
In order to understand the causes and effects of accumulated critical backlog, in the majority of steady state NHS Trusts, an in-depth quantitative review was performed on the remaining 100 Acute Trusts. The Trusts in the shaded region in Figure 3 are the Steady State Trusts. The analyses explored the relationships between the key parameters such as: change in critical backlog per square meter, investment on critical backlog (as a percentage of the income) and Trust age profile.

\section{Descriptive analysis of the sample trust data}

Figure 2 shows the estimated backlog cost in the different backlog categories alongside the actual spend on backlog maintenance during the period of this study. The actual spend was significantly lower than the total estimated backlog cost and very similar to the estimated "high" backlog figure (suggesting that the actual spend was on high and significant backlog).

The size of the NHS backlog problem is significant with total planned critical backlog reported for the 115 Acute Trusts in 2010/11 at £849M (an average of $£ 7.38 \mathrm{M}$ per Trust) and a total actual spend of $£ 238.4 \mathrm{M}$ (an average per Trust of $£ 2.07 \mathrm{M}$ ). The accumulating backlog cost indicates a potential long-term issue resulting in increased risks to patients, visitors and NHS staff.

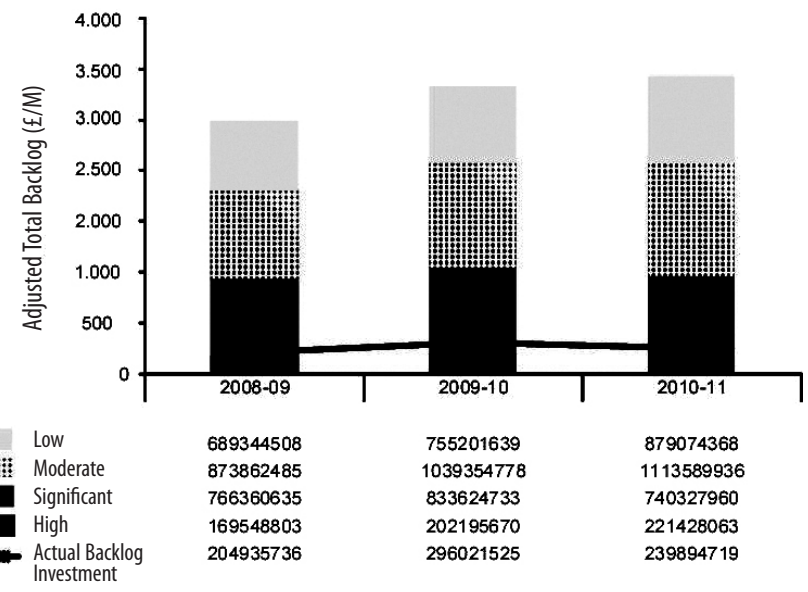

Fig. 2. Estimated cost and actual backlog investment to eradicate backlog in acute NHS trusts in England

Figure 3 illustrates the average change in critical backlog per square meter for each Trust (where a scatter point in Figure 3 depicting a Trust) against the average percentage of income spent on critical backlog maintenance during 2008/09 to $2010 / 11$. The scatter points outside the shaded region in Figure 3 identify the significant change trusts. Income is the total payment an NHS Trust receives for all clinical procedure undertaken. The percentage of income spent on critical backlog is therefore the ratio between income and investment to reduce critical backlog as a percentage. It illustrates that there are two main groups: those

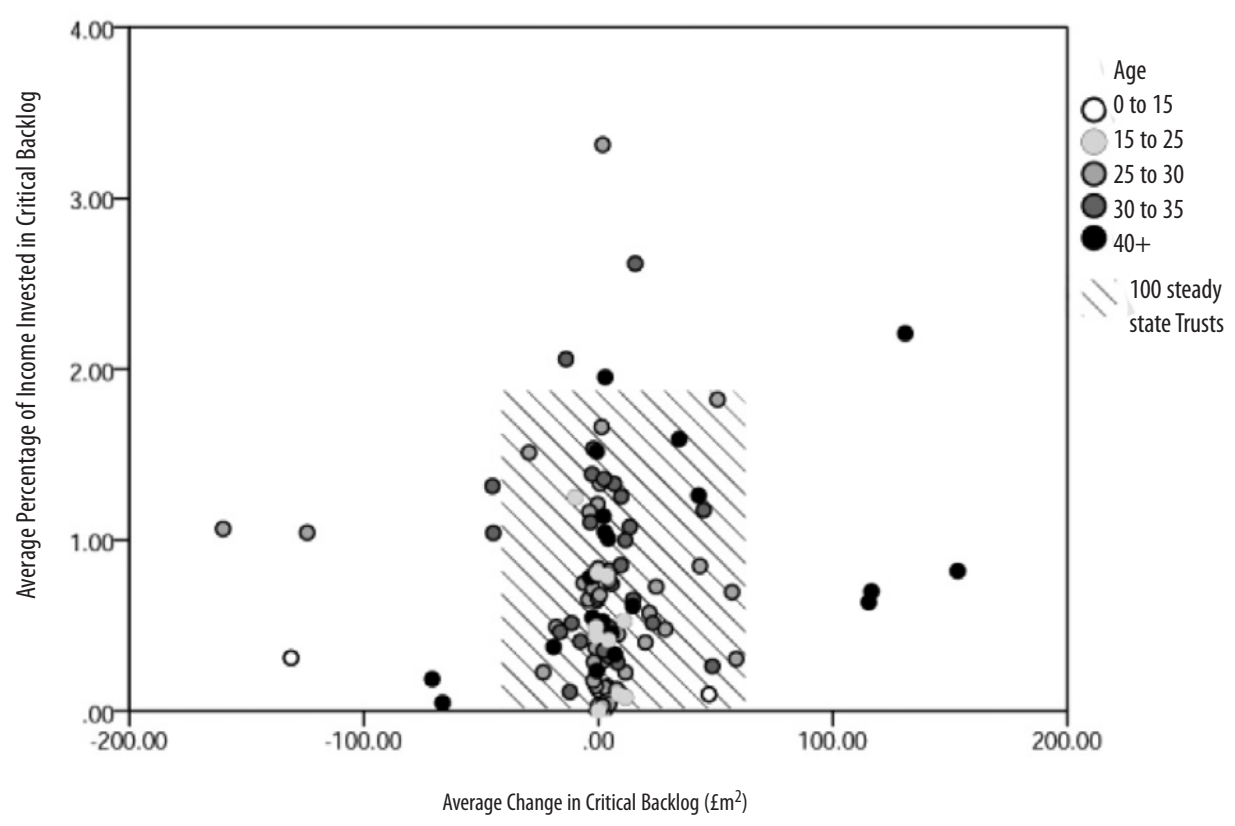

Fig. 3. Average change $\left(£ / \mathrm{m}^{2}\right)$ in critical backlog against average percentage of income spent on critical backlog maintenance (2008/9 to 2010/11) 
100 Trusts maintaining a relative steady state (within the shaded area of Figure 3), and those that are undergoing significant change resulting in major changes in critical backlog (up or down) (i.e. the Significant Change Trusts). All steady state Trusts experienced a total annual increase in critical backlog of $£ 548.33 / \mathrm{m}^{2}$ (an average per Trust of $£ 5.48 / \mathrm{m}^{2}$ and so while they are treated as steady there were relatively small levels of change). The extreme outliers (as seen in Figure 3), are indicative of special circumstances. These outliers were explored further and the high changes in critical backlog were found to be mainly associated with asset acquisition or disposal which had resulted in major changes in floor area and/or changes in age profile. There were high expenditure outliers resulting from reactive approaches for managing emerging high and significant risk issues, such as legionella and fire, and compliance with new regulations and standards to operate the facility. Also, risk management strategies had been employed, for example to minimise capital expenditure resulting in critical backlog cost accumulation prior to new build.

\section{Building portfolio age and critical backlog}

Using data from the 100 steady state Trusts, the relationship between critical backlog and building portfolio age was explored and presented in Figure 4 (for 2008/9-2010/11). To do so, Trust portfolio and critical backlog per square meter figures were grouped and averaged (in order to avoid interferences from trust-by-trust data volatility). The trend suggesting that condition deteriorates with age ap-

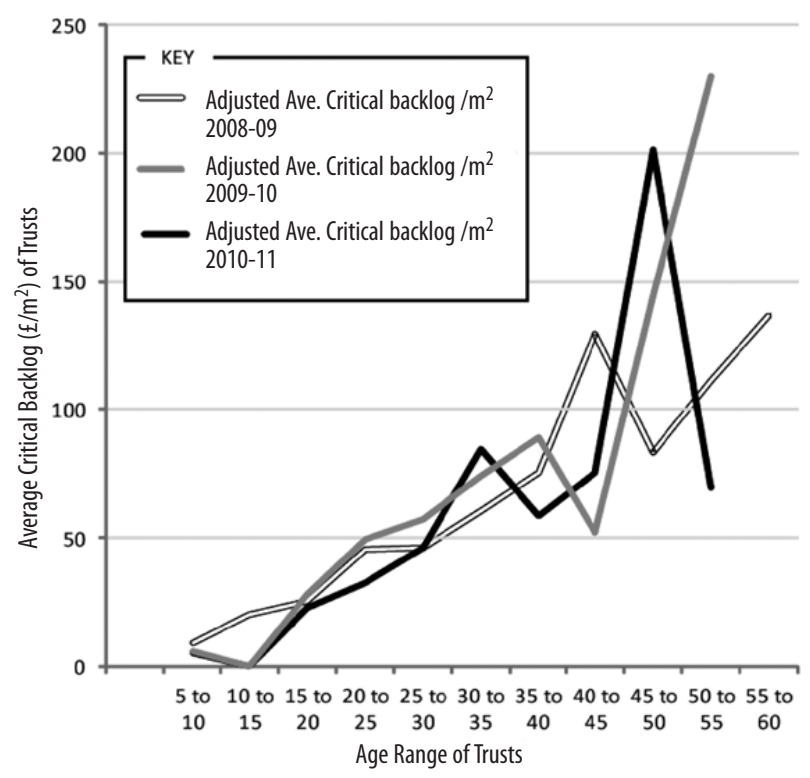

Fig. 4. Average critical backlog by aggregated by estate age range (2008/09 to $2010 / 11)$

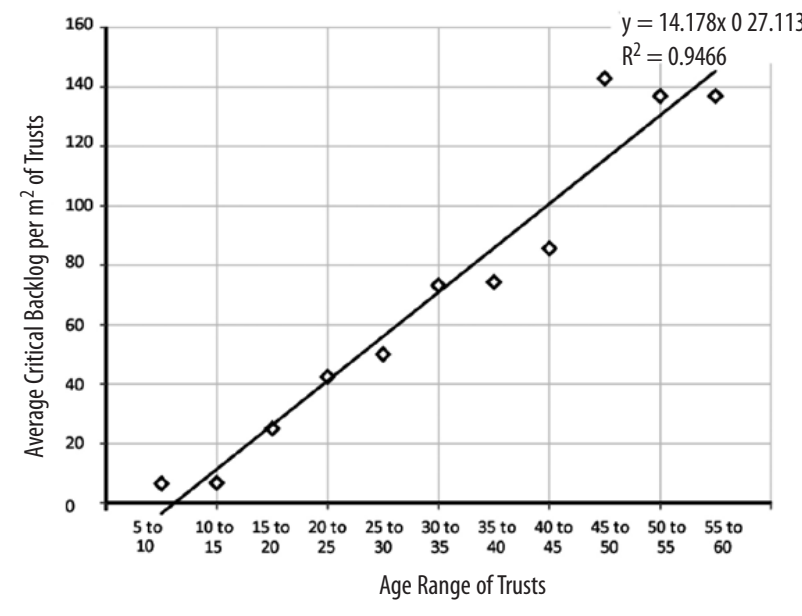

Fig. 5. Average critical backlog aggregated by age range $(2008 / 09$ to $2010 / 11)$

peared, but with increasing variability emerging after the age grouping of $35-40$ years. The data presented in Figure 4 was then aggregated across the three years (2008/9-2010/11) and presented in Figure 5.

Figure 5 hence shows the average critical back$\log \left(£ / \mathrm{m}^{2}\right)$ aggregated across three year against the age range of a Trust building portfolio depicting a statistically significant correlation between accumulated critical backlog and age of the Trust building profile.

The regression model in Equation 1 explains $94 \%$ variability in accumulated backlog with respect to the age of the Trust' building portfolio age $\left(R^{2}=0.9466\right)$. The greater variability after a Trusts chronological age of 35 was indicative of several factors (e.g. decommissioning or disposal). Although it should be noted that at this stage it is not a direct straight line correlation between building age and critical backlog, as it is the mean age of Trusts' building portfolios that have been grouped within age ranges which helps to uncover a relationship with improved correlation. Further work to deal with individual buildings would also help to explore this relationship further.

$$
\begin{aligned}
& \text { Critical backlog } / \mathrm{m}^{2}=14.178 \times \text { Trust age } \\
& \text { group }-27.113 .
\end{aligned}
$$

Table 1(i): presents the average change in critical backlog $\left(£ / \mathrm{m}^{2}\right)$ by income invested on critical backlog and building age range (-ve sign indicates a decrease in critical backlog) and Table 1(ii): presents the percentage of Trusts with decreasing critical backlog, depicting the volume of Trusts per age group that are managing to reduce their critical backlog at their specific investment level. The 
Table 1. Average change in critical backlog per $\mathrm{m}^{2}$ over 2008/09 to 2010/11 for 100 trusts

\begin{tabular}{|c|c|c|c|c|c|c|c|}
\hline & \multicolumn{7}{|c|}{$i$. Change in critical backlog / $\mathrm{m}^{2}$} \\
\hline & Age & 0 to 15 & 15 to 25 & 25 to 30 & 30 to 35 & 35 to 40 & $40+$ \\
\hline \multirow[t]{9}{*}{$\%$ Income invested in backlog } & $0-0.5$ & 0.012 & 3.8 & 4.7 & 4.5 & 4 & 5.47 \\
\hline & $0.5-1$ & & 4.7 & 1 & 3.7 & 7.7 & 2.2 \\
\hline & $1-1.5$ & & -9.8 & 0.2 & -3.8 & 4.2 & 3 \\
\hline & $1.5-2$ & & & & -10 & & 12.3 \\
\hline & $2-2.5$ & & & & & -13.8 & \\
\hline & $3-3.5$ & & & & 1.9 & & \\
\hline & Estimate: & $\sim 0.5 \%$ & $\sim 1 \%$ & $\sim 1.5 \%$ & $\sim 1.5 \%$ & $\sim 2 \%$ & $\sim ? \%$ \\
\hline & \multicolumn{7}{|c|}{ ii. Percentage No. of trust per age group with decreasing critical backlog (\%) } \\
\hline & Age & 0 to 15 & 15 to 25 & 25 to 30 & 30 to 35 & 35 to 40 & $40+$ \\
\hline \multirow[t]{6}{*}{$\%$ Income invested in backlog } & $0-0.5$ & $40 \%(5)$ & $30 \%(6)$ & $30 \%(6)$ & $25 \%(12)$ & $37 \%(8)$ & $25 \%(4)$ \\
\hline & $0.5-1$ & & $30 \%(3)$ & $80 \%(5)$ & $43 \%(7)$ & $17 \%(6)$ & $40 \%(5)$ \\
\hline & $1-1.5$ & & $100 \%(1)$ & $50 \%(2)$ & $100 \%(1)$ & $33 \%(9)$ & $0 \%(3)$ \\
\hline & $1.5-2$ & & & & $67 \%(3)$ & & $33 \%(3)$ \\
\hline & $2-2.5$ & & & & & $100 \%(1)$ & \\
\hline & $3-3.5$ & & & & $0 \%(1)$ & & \\
\hline
\end{tabular}

figures in brackets show the number of Trusts in each age group. For example, for Trusts investing $1-1.5 \%$ income on critical backlog, $100 \%$ of Trusts (all Trusts) with an average building age of 15-25 years have decreased critical backlog on average by $£ 9.8 / \mathrm{m}^{2}$, however, it should be caveated by the fact that only one Trust lies within this age group.

Trusts not significantly spending on backlog were subsequently accumulating critical backlog. Relatively steady state characteristics maybe attributed to several factors, including: time taken to receive planning permissions, delays in receiving capital receipts, inappropriate infrastructure planning cycles, unsuitable or non-existent space for decanting, lack of operational slack and performance targets, inaccuracy in data collection and management, difficulties in gaining board commitment and issues with obtaining capital (due to other competing equipment asset purchases and movement towards Foundation Trust status). In addition, the importance of not reducing backlog prior to significant capital investment and demolition (rather managing it instead) may be seen as delivering good value for money for the taxpayer.

\section{LIMITATIONS}

This paper reports on the quantitative analysis of 115 Acute Trusts (2008/9 to 2010/11). Within a large multi-organisational data set data anomalies are understandable. This study, as per Ive et al. (2010), used publically available data, which provided a valuable source for analysis. However, there were recorded instances where data appeared to be duplicated (through the misallocation of costs aggregated and spread across building sites), reporting errors, low or missing values and extreme outliers. What is more during the period of investigation some hospitals were amalgamated, others re-named, or were sold to independent healthcare providers. Limitations include:

i. Twenty percent of the original 160 Acute NHS Trusts did not have data relevant for our analysis such as income and backlog maintenance. There were instances where some Trusts had reported the same backlog value over consecutive years indicating possible data discrepancies. Furthermore, there were cases where the risk adjusted backlog cost did not tally with the backlog costs in the separate risk categories. We removed Trusts with missing variable values for the purpose of our analysis.

ii. Finally, this paper draws on aggregated data from 115 Trusts from the NHS building portfolio rather than investigating NHS providers on a Trust by Trust basis. It uses ERIC figures for building age, Trust gross internal floor area and backlog that are aggregated figures at a Trust/organisational level. This introduces an averaging effect. In actuality, many Trusts will have significant variability in their asset portfolio with some new and some old buildings, and so caution must be taken when applying these findings at the scale of the building. Further research is 
needed to understand how building specific age groupings impact critical backlog. What is more, age is only one of a number of indicators, for example some older Victorian buildings may be easier and less costly to maintain than some of the buildings built in the $60 \mathrm{~s}$ and $70 \mathrm{~s}$. Also the implications of new built assets delivered through Private Finance Initiative (PFI), may have higher maintenance cost, decreased risk and closely monitored performance. This needs further exploration if future predictions are to be made by building on for example work completed by Ive et al. (2010) which concluded that PFI hospitals tend to have higher performance in aspects of patient environment, cleanliness and to some extent catering, at seemingly no higher costs. Although these findings were caveated on the basis of data and sampling uncertainties (as in this paper).

\section{DISCUSSION}

This paper has demonstrated empirical support for a causal relationship between NHS Trust building portfolio age and critical backlog accumulation and for its use in regulation and new asset management approaches. It strengthens the inference made by other researchers that older facilities have higher maintenance cost and accumulate critical backlog if not well managed, although authors such as Pfründer et al. (2007) and Bahr and Lennerts (2008a, 2008b) found a much more dramatic deterioration at 30 years in total maintenance cost. A steadier decline in critical backlog maintenance is reported in this article. Although few comparative differences can be drawn, between this and other studies, due to variances in definition and accounting method. Further research is needed to form international benchmarks and wider generalisations. Furthermore, we cannot account for the subjectivity in reported maintenance costs and maintenance budgeting that has been reported elsewhere (Bahr, Lennerts 2008a). Significant opportunities exist to develop a more advanced approach to strategic asset management that could have significant implications on Trusts financial planning activities.

This paper has shown the following general findings.

i. A regression analysis indicated that critical backlog accumulation increases as the age profile of a Trust's building portfolio increases. However, what is certain is that a relation between building portfolio age and accumulation of critical backlog needs to be better understood so that expenditure to stop backlog increasing can be allocated. More data and analysis are therefore required at a lower level of resolution to account for the averaging effect of multiple buildings within a NHS Trust portfolio and in build quality in different decades of construction.

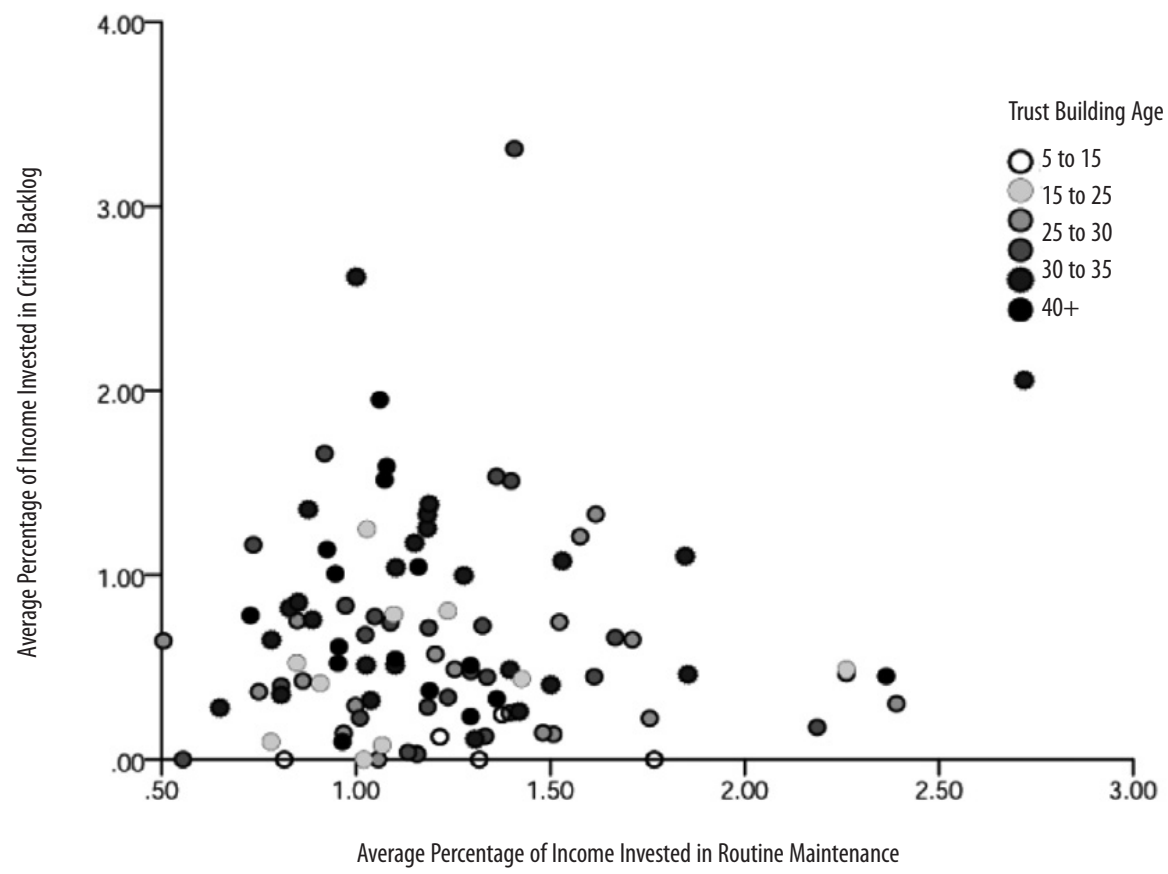

Fig. 6. Average percentage of income spent on backlog and routine maintenance (2008/9 to 2010/11) 


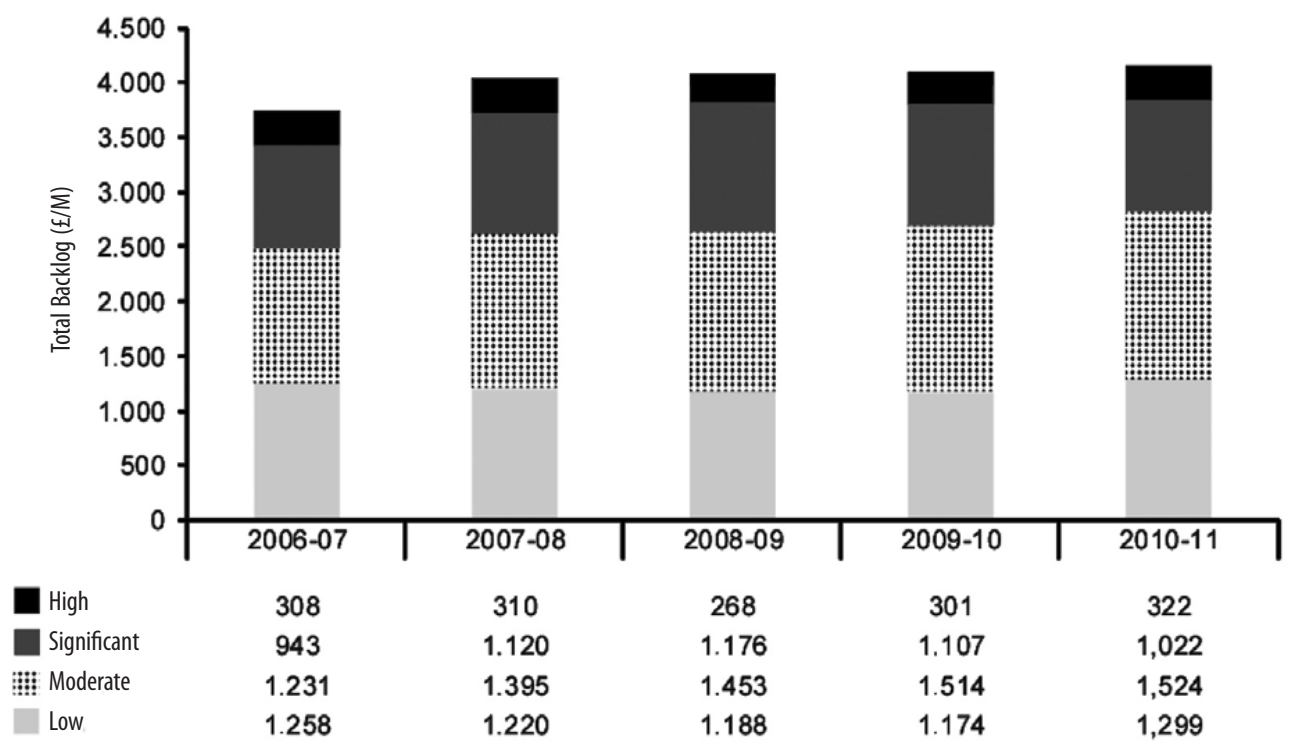

Fig. 7. Estimated cost to eradicate backlog in acute trusts (Source: DH)

ii. 'Significantly changing' Trusts are both increasing and decreasing critical infrastructure risks. This shows that change is not always for the better. When a Trust undergoes substantial changes in floor area or age profile there can be significant impacts on critical backlog. Further analysis showed that Trusts with a better starting position (lowest critical backlog in the sample) often remained in a steady state; while Trusts with a high starting baseline faced more volatility in backlog increases or reductions. This appears to suggest that high backlog positions can be significantly reduced and Trusts with very high backlog could experience rapidly increasing backlog. Figure 6 shows average percentage of income invested in backlog against the average percentage of income invested in routine maintenance across 2008/09 to 2010/11 (each scatter point depicting a Trust). It illustrates a common significant cluster of similar values) 0.00 to 1.5 for both investment in backlog and routine maintenance. However, there is variability in the ratio between routine maintenance and backlog maintenance. Reviewing these figures by age showed very little apart from the fact that those Trusts with the youngest building age profile ( 5 to 15 years and probably PFIs) were returning very low backlog, as is to be expected.

iii. Age of the building can be used as a proxy for critical infrastructure backlog and building condition. It can also act as a proxy for cost of maintenance, depreciation and performance outcome, although this work needs further exploration. iv. During the 2006/7 to 2010/11 period, Figure 7 shows that high and significant risk backlog increases from $£ 1.251$ bn to $£ 1.344$ bn (according to actual returns to DH and not adjusted for inflation). The annual change may appear relatively small but indicates a potential long-term issue resulting in increased risks to patients, visitors and NHS staff. The forecasting of future impacts such as these requires further investigation.

With greater understanding of the implications of built asset age on condition and so critical backlog the NHS will be better able to assure investment in infrastructure routine maintenance and greater Trust funding commitments concerning percentage of income invested on backlog, this will help ensure that critical backlog does not accumulate at the same rate. In addition, given the severity of economic pressures there is a need to forecast the impact of limited capital spending and low maintenance costs over a 20 year period through the development of a national approach to predictive analytics for building maintenance. Asset management approaches should use advanced statistical modelling, machine learning, and data mining techniques in the analysis of current and historical facilities management facts to make predictions about future, or otherwise unknown, events and scenarios to minimise risk and maximise value. In addition, advancing sensor and computer-aided building information modelling and computerised maintenance management approaches (McKenna, Oliverson 1997) require greater application within the NHS. 


\section{CONCLUSION AND RECOMMENDATIONS}

It has been shown that Trust building portfolio age has a significant impact on critical backlog, and could drive the development of new asset management approaches. This knowledge will also drive policy decision making to understand the impact of age on national maintenance programmes with regards to risk-adjusted backlog, failure criticality and depreciation. In addition, a smarter national approach to strategic asset management in healthcare infrastructure is required (Mills et al. 2011, 2012; Mahadkar et al. 2011). National policy makers may thus be better able to categorise this starting position to drive greater predictability in the eradication of backlog and in designing programmes of capital spending.

Trusts need to adopt appropriate levels of continued investment in routine and backlog maintenance to ensure critical backlog is reduced and does not accumulate once eradicated. Current trends suggest that most Trusts need to invest between 0.5 and 1.5 per cent of income (depending upon current levels, age profile, location etc.) to simply maintain critical backlog levels aligned with their unique financial, operational and clinical strategies. There needs to be similar levels spent on routine maintenance, however further research is needed to determine the optimum ratio of these two. Table 2 shows the results of the Steady State Trusts. It provides a guideline estimate of the investment on backlog as a percentage of income by building age that Trusts may need to spend to help avoid future accumulation of critical backlog. Critical backlog has required some Trusts to make major capital investment and deliver robust asset management strategies to overcome past accumulations. What is certain is that the problem of backlog will continue to grow if government and Trusts do not act on the natural deterioration caused by built asset portfolio aging.

The results of this healthcare-specific building sample show that further investigation and research would be worthwhile and timely. There is a need to explore the impact of building age on condition to make comparison of procurement and contracting approach, public and private operators and typologies of different healthcare buildings and subsequent spaces. It is well known that changing design, material and equipment selection and construction methods have a significant impact on maintenance cost (Al-Hammad 1997; Arditi 1999; CABE 2008); so generalising and predicting future critical backlog is problematic. Furthermore, this wide-ranging analysis of the whole NHS asset portfolio should be investigated at a lower level of resolution (within specific Trusts and at a building and elemental scale) to investigate with more granularity specific components, failures, faults, symptoms, features and measures. In addition the investigation of the evidence that supports causal relationship between healthcare building age, building condition and clinical health outcomes requires future exploration. Finally, predictive analytics should be developed to advance the causal connection between conditions.

Regulatory systems must keep pace with organisational developments in quality management as they become more advanced in their ability to standardise, inspect, control, assure and predict the delivery of value. Both are dependent on a difference between "detection" and "prevention" (Baldwin et al. 2012). The cost of the latter (in assuring that work is done right first time) is often greater than the former, although also carries greater risk of failure (Dale, Plunkett 1999). The evolution of quality management within NHS organisations from inspection through quality control and quality assurance to total asset management has coincided with a move from centralised control through direct action and incentives to co-production and smart networked approaches (Mills et al. 2012).

As governments apply less regulatory control (as in the NHS in England), organisations must pick up new responsibilities for co-producing results and assuring asset quality. Perhaps most important are the opportunities for applying and integrating benchmarking regimes between national regulators and organisational quality management systems (in Trusts and construction organisations). There is growing appreciation of the potential value of pooled and centralised data. As such, policy makers and practitioners are determined to improve the quality of returns and the feedback that supports benchmarking and prediction. This research has provided an example data application, and has illustrated the potential for predictive analytics.

Table 2. Estimated investment to maintain backlog by age

\begin{tabular}{lllllll}
\hline Age & 0 to 15 & 15 to 25 & 25 to 30 & 30 to 35 & 35 to 40 & $40+$ \\
\hline Estimate: & $\sim 0.5 \%$ & $\sim 1 \%$ & $\sim 1.5 \%$ & $\sim 1.5 \%$ & $\sim 2 \%$ & $\sim ? \%$ \\
\hline
\end{tabular}


In this paper, we have explored the opportunities for capitalising on an understanding of the dynamic impact of Trust building portfolio age on condition (and so risk, performance and value), to deliver greater premises assurance whatever the regulatory structure and to advance the field of asset management to enable new predictive approaches to be developed.

\section{ACKNOWLEDGEMENTS}

The research reported in this paper was funded in part by a Loughborough University ESPRC IMCRC (EP/E002323/1) and EPSRC HaCIRIC (Health and Care Infrastructure Research and Innovation Centre) core grants (EP/D039614/1 and $\mathrm{EP} / \mathrm{I029788/1)}$ in addition to funding from the DH. We also acknowledge those from the DH and NHS Trusts who have participated in related interviews and focus groups.

\section{REFERENCES}

Al-Hammad, A.; Assaf. S.; Al-Shihah, M. 1997. The effect of faulty design on building maintenance, Journal of Quality in Maintenance Engineering 3(1): 29-39. http://dx.doi.org/10.1108/13552519710161526

Appleby, J.; Crawford, R.; Emmerson, C. 2009. How cold will it be? Prospects for NHS funding 2011-17. The King's fund.

Arditi, D.; Nawakorawit, M. 1999. Issues in building maintenance: property managers' perspective, Journal of Architectural Engineering 5(4): 117-132. http:// dx.doi.org/10.1061/(ASCE)1076-0431(1999)5:4(117)

Bahr, C.; Lennerts, K. 2008a. Identification of building- and usage-dependent parameters with significant impact on maintenance expenditure via lifecycle analysis, in EFMC 2008 European Facility Management Conference (EuroFM), 10-11 June 2008, Manchester, UK.

Bahr, C.; Lennerts, K. 2008b. Planung von instandhaltungskosten [Planning of maintenance costs], in Facility Management Messe und Kongress, 6-8 May 2008, Frankfurt am Main, Veranstalter, MESAGO Messe Frankfurt GmbH, Stuttgart.

Bahr, C.; Pfründer, U.; Lennerts, K. 2008. Maintenance budgeting methods, in CIB W70 International Conference in Facility Management, Achieving Healthy and Creative Facilities, 16-18 June 2008, Heriot Watt University, Edinburgh.

Baldwin, R.; Cave, M.; Lodge, M. 2012. Understanding regulation: theory, practice, and strategy. Oxford: Oxford University Press.

Berry, L. L.; Parker, D.; Coile, R. C. J.; Hamilton, D. K.; O'Neill, D. D.; Sadler, B. L. 2004. The business case for better buildings, Frontiers of Health Services Management 21: 1-24.
Bjorberg, S.; Verweij, M. 2009. Life-cycle economics: cost, functionality and adaptability, in Rechel, B.; Wright, S.; Edwards, N.; Dowdeswell, B.; McKee, M. (Eds.). Investing in hospitals of the future. London, World Health Organization on behalf of European Observatory on Health Systems and Policies.

Bossmann, J.; Lennerts, K. 2013. Maintaining building facilities - a growing challenge, in International Conference on Construction and Real Estate Management (ICCREM), 10-11 October 2013, Karlsruhe, Germany. http://dx.doi.org/10.1061/9780784413135.028

Bourke, K.; Ramdas, V.; Singh, S.; Green, A.; Crudgington, A.; Mootanah, D. 2005. Achieving whole life value in infrastructure and buildings. Bracknell: BRE.

BSI. 2000. Building and Constructed Assets - Service Life Planning: Part 1: General principles. London: BSI.

BSI. 2001. Building and Constructed Assets - Service Life Planning: Part 2: Service life prediction procedures. London: BSI.

BSI. 2002. Building and Constructed Assets - Service Life Planning: Part 3: Performance audits and reviews. London: BSI.

BSI. 2004a. Building and Constructed Assets - Service Life Planning: Part 3: Maintenace and life cycle costing. London: BSI.

BSI. 2004b. Building and Constructed Assets - Service Life Planning: Part 6: Procedures for considering environmental impacts. London: BSI.

BSI \& BCIS. 2008. Standardised method of life cycle costing for construction procurement: a supplement to ISO 15686-5. London: BSI.

CABE. 2008. The cost of bad design. London.

CalCon. 2014. EPIQR. Available at: http://www.calcon. de/de [accessed on January 2014].

Campbell, J. D.; Jardine, A. K. S.; McGlynn, J. 2011. Maintenance excellence, optimizing equipment lifecycle decisions (Dekker mechanical engineering). England, CRC Press.

Care Quality Commission. 2010. Guidance about compliance: summary of regulations, outcomes and judgement framework, March 2010.

Circle. 2014. We believe hospitals can be better. Available at: http://www.circleholdingsplc.com/uploads/document/file/66/circle_holdings_interim_report_2014.pdf [accessed on January 2014].

Dale, B. G.; Plunkett, J. J. 1999. Quality costing. Aldershot, Hants, Gower Press.

Department of Health. 2010. Estates return information collection (ERIC) 2009/10. Leeds: DH.

Department of Health. 2012a. Briefing notes on Government amendments to the Health and Social Care Bill: Lords Report Stage, Crown.

Department of Health. 2012b. NHS premises assurance model (PAM). Available at: https://www.gov.uk/government/publications/nhs-premises-assurance-model-launch [accessed on June 2013].

DH. 2008. The Health and Social Care Act 2008: Code of Practice on the prevention and control of infections and related guidance, Department of Health, Crown. 
Diez, K.; Lennerts, K. 2009a. Facility management costs in the OR - a process model, E(Hospital) 3.

Diez, K.; Lennerts, K. 2009b. A process-oriented analysis of facility management services in hospitals as a basis for strategic planning, Journal of Facilities Mangement 7: 52-60. http://dx.doi. org/10.1108/14725960910929565

Francis, R. 2013. Report of the Mid Staffordshire NHS Foundation Trust Public Inquiry, in Commons, H. O. (Ed.). London: The Stationery Office.

Harker, R. 2012. Social and general statistics, NHS funding and expenditure. House of Commons.

Indian Health Service. 1997. Technical handbook for environmental health and engineering. The Federal Health Program for American Indians and Alaska Natives.

Interserve. 2014. Leicester, Leicestershire and Rutland NHS Trusts: a new model, health sector case study. Available at: http://www.interserve.com/about-interserve/case-studies/2161/leicester-leicestershireand-rutland-nhs-trusts--a-new-model [accessed on January 2014]

Ive, G.; Murray, A.; Edkins, A.; Rintala, K. 2010. Cost and performance comparison of PFI and non-PFI healthcare infrastructure in England, in HaCIRIC10 Better Health through Better Infrastructure, 22-24 September 2010, Edinburgh, Scotland.

Lavy, S.; Shohet, I. M. 2007. A strategic integrated healthcare facility management model, International Journal of Strategic Property Management 11: 125-142. http://dx.doi.org/10.1080/164871 5X.2007.9637565

Lennerts, K. 2010. Quantitative validation of budgeting methods and suggestion of a new calculation method for the determination of maintenance costs, Journal of Facilities Management 8: 47-63. http://dx.doi. org/10.1108/14725961011019076

Lennerts, K.; Abel, J.; Pfründer, U.; Sharma, V. 2005. Step-by-step process analysis for hospital facility management: an insight into the OPIK research project, Facilities 23: 164-175. http://dx.doi. org/10.1108/02632770510578539

Mahadkar, S.; Mills, G. R. W.; Astley, P.; Hind, R.; Price, A. 2011. Strategic asset management: relating to open building concepts, in Architecture in the fourth dimension: methods and practices for a sustainable building stock, 15-17 November 2011, Boston, Mass, USA.

McKenna, T.; Oliverson, R. 1997. Glossary of reliability and maintenance terms. Houston, Texas, Gulf Publilshing Company.

Mills, G. R. W.; Erskine, J.; Price, A. D. F.; Ricks, E.; Phiri, M.; Sellars, P. 2012. Developing a world-leading and smart regulatory design quality framework for healthcare estates in England, in HaCIRIC International Conference. Transforming Healthcare Infrastructure and Services in an Age of Austerity, 19-21 September 2012, Cardiff, UK.

Mills, G. R. W.; Mahadkar, S.; Price, A. D. F.; Wright, S. 2011. Lean strategic asset management: integrating value, flow and capacity provision in the UK heath sector, in 19th Annual Conference of the International Group for Lean Construction (IGLC 19), 13-15 July 2011, Lima, Peru.

National Surface Transportation Policy and Revenue Study Commission. 2007. Transportation for tomorrow: report of the National Surface Transportation Policy and Revenue Study Commission.

NHS Estates. 1997. An exemplar operational risk management strategy. The Stationary Office (TSO).

NHS Estates. 2004. Best practice advice - establishing and managing backlog. UK, Department of Health.

Nyce, C. 2007. Predictive analytics white paper. American Institute for CPCU.

Pfründer, U.; Bahr, C.; Lennerts, K. 2007. Lebenszyklusorientierte Strategie zur Instandhaltung öffentlicher Immobilien Ergebnisse aus dem Forschungsprojekt BEWIS [Life cycle oriented strategy for the maintenance of public property - results from the research project BEWIS], in Proceedings of the Facility Management Messe und Kongress, 24-26 April 2007, Frankfurt am Main. Berlin: VOE VERLAG GMBH.

Phiri, M. 2006. Does the physical environment affect staff and patient health outcomes? A review of studies and articles 1965-2006. Department of Health. London, TSO.

Price, I. 2007. Lean assets: new language for new workplaces, California Management Review 49(2): 102118. http://dx.doi.org/10.2307/41166385

Price, I.; May, D. 2008. Lean healthcare assets challenge FM performance measurement conventions, in EFMC 2008 European Facility Management Conference (EuroFM), 10-11 June 2008, Manchester, UK.

Sadler, B. L.; Guenther, R.; Hamilton, D. K.; Hessler, F. A.; Merritt, C.; Parker, D. 2011. Fable hospital 2.0: the business case for building better health care facilities, Hastings Center Report 41: 13-23.

Sharp, J. M.; Irani, Z.; Desai, S. 1999. Working towards agile manufacturing in the UK industry, International Journal of Production Economics 62: 155-169. http://dx.doi.org/10.1016/S0925-5273(98)00228-X

Ulrich, R.; Quan, X.; Zimring, C.; Joseph, A.; Choudhary, R. 2004. The role of the physical environment in the hospital of the 21st century: a once-in-a-lifetime opportunity. Report to the center for health design for the designing the 21st century hospital project. Available at: https:/www.healthdesign.org/sites/default/files/Role\%20Physical\%20Environ $\% 20 \mathrm{in} \% 20$ the $\% 2021$ st $\% 20$ Century\%20Hospital_0.pdf [accessed on June 2013].

Ulrich, R. S.; Zimring, C.; Zhu, X.; DuBose, J.; Seo, H.-B.; Choi, Y.-S.; Quan, X.; Joseph, A. 2008. A review of the research literature on evidence-based healthcare design, HERD 1(3): 61-125. http://dx.doi. org/10.1177/193758670800100306

Yusuf, Y. Y.; Sarhadi, M.; Gunasekaran, A. 1999. Agile manufacturing: the drivers, concepts and attributes, International Journal of Production Economics 62: 33-43. http://dx.doi.org/10.1016/S09255273(98)00219-9 